\title{
Declining trends in some sexually transmitted diseases in Belgium between 1983 and 1989
}

\author{
D Walckiers, P Piot, A Stroobant, J Van der Veken, E Declercq
}

\begin{abstract}
Objective-To examine trends in some sexually transmitted diseases in Belgium and to discuss them in the light of the European background.

Design-Analysis of the time trends of $C$ trachomatis and $N$ gonorrhoeae infections diagnosed by a network of microbiological laboratories, and of male urethritis diagnosed by a network of general practitioners.

Setting-Belgium.

Subjects-Reports of $C$ trachomatis and $N$ gonorrhoeae infections by a network of microbiological laboratories, and of male urethritis by a network of general practitioners, to the Institute of Hygiene and Epidemiology.

Results-Whereas an increase in the number of $\boldsymbol{C}$ trachomatis infections, more pronounced among women, was observed up to 1986, a small decrease has been observed afterwards in males. The mean number of chlamydial infections per laboratory and per year was $4 \cdot 2$ in $1983,15.7$ in 1986 and 13.9 in 1989. A decrease in the number of $\boldsymbol{N}$ gonorrhoeae infections, more pronounced among men, has been observed. The mean number of cases of gonorrhoea per laboratory and per year was 10.9 in 1983 and only $2 \cdot 2$ in 1989 . The same declining trend has been observed in another surveillance programme of male urethritis, based on a network of general practitioners. The number of cases of male urethritis per 100 patient encounters went down from 0.06 in 1982-3 to 0.04 in 1988-9.

Conclusion-The declining trend in Western Europe in incidence of gonococcal infections and of urethritis in men is also occurring in
\end{abstract}

Institute of Hygiene and Epidemiology, Section of Epidemiology, Wytsmanstreet 14, 1050 Brussels, Belgium

D Walckiers; A Stroobant, J Van der Veken; E Declercq

Institute of Tropical Medicine, Department of Microbiology, Nationalestreet 155, 2000 Antwerp, Belgium

P Piot
Belgium, but genital chlamydial infections remain an important public health problem.

\section{Introduction}

Over recent years, changes in the trends of some sexually transmitted diseases have been reported in different European countries such as the Nordic countries, the Netherlands, France, Great Britain and Switzerland..$^{1-7}$

In Belgium, a national laboratory reporting network has been collecting, since February 1983, epidemiological data about a selected number of micro-organisms including Chlamydia trachomatis and Neisseria gonorrhoeae. ${ }^{8}$ On the other hand, a sentinel surveillance of male urethritis has also been organised through a network of general practitioners. ${ }^{9}$ This paper describes the trends observed in $C$ trachomatis and $N$ gonorrhoeae infections over a seven year period, and compares these laboratory findings with the general practitioners data about male urethritis in Belgium. These results are also discussed in the light of the European background.

\section{Materials and methods \\ Laboratories registration}

During the period 1983-9, $73(18 \%)$ out of the 397 clinical microbiology laboratories in the country participated, on a voluntary basis, in the registration programme: they serve as sentinel laboratories. These 73 sentinel laboratories are spread over 32 of the 43 districts of the country and most of them are hospital laboratories.

Initially, a case of chlamydial or gonococcal infection was defined as a patient from whom the respective micro-organisms were isolated by culture. Since 1 April 1985, bacterial antigen detection by enzyme immunoassay (EIA) and immunofluorescence test (IF) are included in the registration programme.

Report forms are returned weekly even if no cases are registered. Multiple or repeat diagnoses from the same patient during one disease episode are not reported. Recorded data include the patient's age and sex, source of specimen, diagnostic method and some other information such as penicillinase production, presence of other infections and clinical symptoms. ${ }^{8}$

The mean number of cases per laboratory and per year was calculated by dividing the number of cases 
registered by the number of registration weeks and multiplying this by the 52 weeks of one year.

\section{General practitioners registration}

A similar system based on sentinel general practitioners has also been organised on a country scale and includes infectious as well as non infectious conditions. ${ }^{9}$ In $1982-3^{10}$ and in $1988-9,{ }^{11}$ all cases of gonococcal and non-gonococcal urethritis in males were registered over a period of one year. It is indeed estimated that almost $90 \%$ of these cases are seen by general practitioners and not by specialists. ${ }^{12}$ Thirty one general practitioners participated in the surveillance programme during both registration periods.

A case of male urethritis was defined as a patient with dysuria and/or purulent, mucopurulent or mucoid discharge. The recording includes patients consulting for the first time with an episode of urethritis as well as patients with a known history of urethritis, consulting again after complete recovery of a previous episode. The patient is only recorded once per episode (first consultation).

The significance of differences was tested with chi square analysis.

\section{Results}

\section{Sentinel laboratories}

During the 1983-9 observation period, the same 73 laboratories participated in the surveillance programme on a very regular basis: the percentage of weekly report forms returned varied between 92 and $98 \%$ for each year. Since the beginning of the surveillance programme, the diagnosis of $C$ tracho- matis infections has been most frequently based on the ELISA technique (alone or in association; $71 \%$ in 1985 and $65 \%$ in 1989).

Whereas at the beginning of the programme, $81 \%$ of the diagnoses of $N$ gonorrhoeae infections were based on culture, a decrease in this percentage was observed up to $1988(50 \%)$, but an increase in the relative use of culture was again observed in 1989 $(67 \%)$. An increase in the use of the ELISA technique was observed until 1988, when $56 \%$ of the diagnoses were based on this method. In 1989 this percentage was only $37 \%$.

The number of laboratories having reported at least one case of $C$ trachomatis infection went up from 18 in 1983 to 39 in 1986 and 45 in 1989. An increase in the number of chlamydial infections, more pronounced among women, was observed up to 1986 (fig). A small decrease has been observed afterwards in males. The mean number of chlamydial infections per laboratory and per year was 4.2 in $1983,15 \cdot 7$ in 1986 and 13.9 in 1989.

The number of laboratories having reported at least one case of $N$ gonorrhoeae infection was 62 in 1983 and only 33 in 1989 . The figure shows a decrease in the number of gonorrhoea cases during the whole registration period. This decrease has been more pronounced since 1985 although antigen detection of this infection was then for the first time included in the surveillance programme. The mean number of cases of gonorrhoea per laboratory and per year was 10.9 in 1983 and only $2 \cdot 2$ in 1989.

The decrease in the number of $N$ gonorrhoeae infections has been particularly striking among men. A small increase in the number of infections among

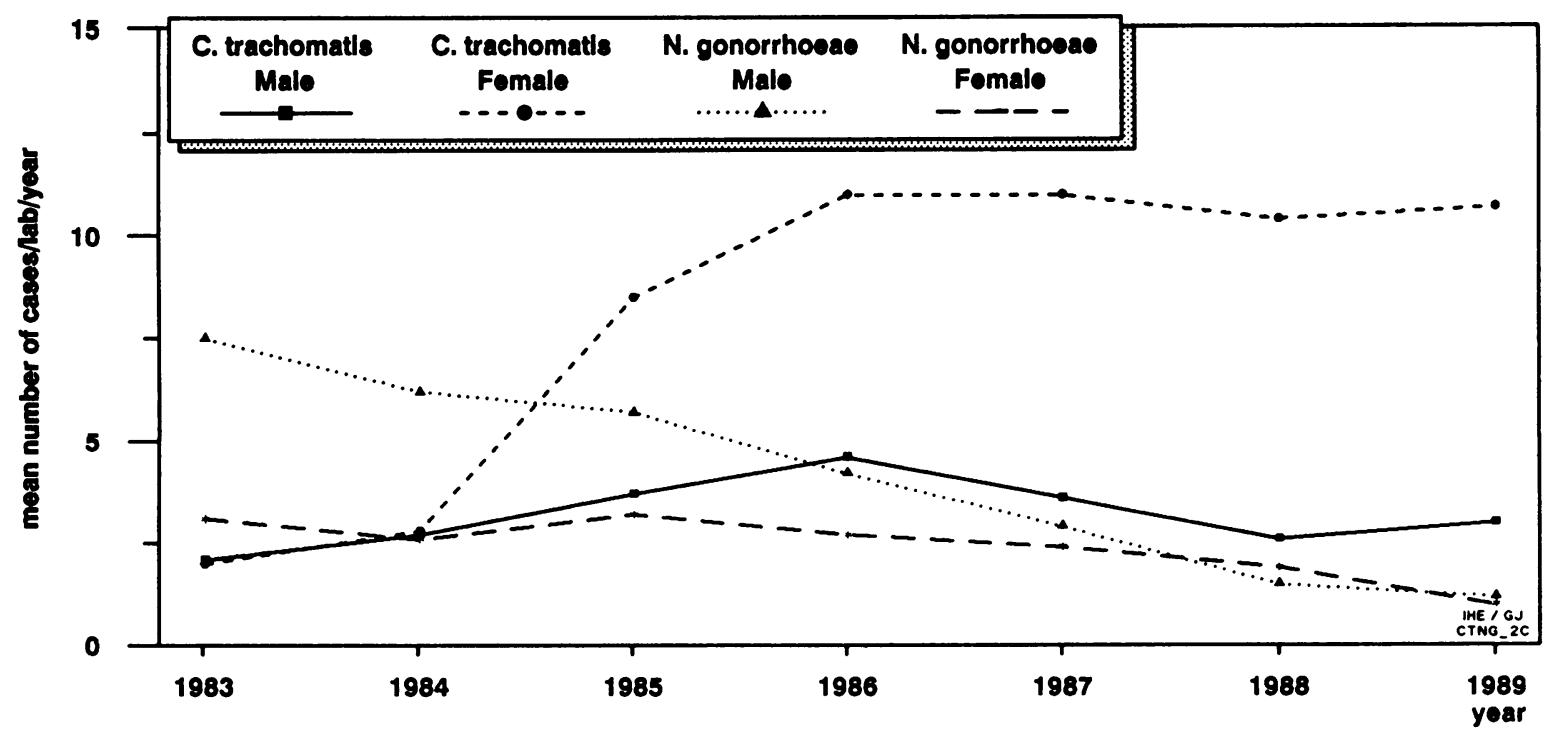

Figure $C$ trachomatis, $N$ gonorrhoeae: frequency of diagnosis reporting by sentinel laboratories, according to patient's sex. 
Table 1 Sex ratio of patients in cases of $C$ trachomatis and $N$ gonorrhoeae infections diagnosed by sentinel laboratories

\begin{tabular}{|c|c|c|c|c|c|c|}
\hline $\begin{array}{l}\text { Ratio of male to } \\
\text { female cases }\end{array}$ & $\begin{array}{l}31 \text { Jan } 1983- \\
31 \text { March } 1985\end{array}$ & $\begin{array}{l}1 \text { April 1985- } \\
29 \text { December } 1985\end{array}$ & 1986 & 1987 & 1988 & 1989 \\
\hline $\begin{array}{l}C \text { trachomatis } \\
N \text { gonorrhoeae }\end{array}$ & $\begin{array}{l}\mathrm{N}=769 \\
0 \cdot 9 \\
\mathrm{~N}=1480 \\
2 \cdot 3\end{array}$ & $\begin{array}{l}\mathrm{N}=723 \\
0 \cdot 4 \\
\mathrm{~N}=424 \\
1 \cdot 8\end{array}$ & $\begin{array}{l}N=1117 \\
0 \cdot 4 \\
N=502 \\
1 \cdot 5\end{array}$ & $\begin{array}{l}\mathrm{N}=1049 \\
0 \cdot 3 \\
\mathrm{~N}=381 \\
1 \cdot 2\end{array}$ & $\begin{array}{l}\mathrm{N}=922 \\
0 \cdot 2 \\
\mathrm{~N}=241 \\
0 \cdot 8\end{array}$ & $\begin{array}{l}\mathrm{N}=927 \\
0 \cdot 3 \\
\mathrm{~N}=146 \\
1 \cdot 1\end{array}$ \\
\hline
\end{tabular}

women was observed in 1985, at the time antigen detection was included in the surveillance programme. A decrease has also been observed since then.

For both infections, an increase in the proportion of women has been observed. At the moment the percentage of infections diagnosed in women reaches about $80 \%$ for $C$ trachomatis and $50 \%$ for $N$ gonorrhoeae. As a result, table 1 shows, for $C$ trachomatis and $N$ gonorrhoeae, a decrease in the ratio of male to female cases.

Before antigen detection of these infections was included in the registration programme (31 January 1983 to 31 March 1985), 45\% of the $C$ trachomatis infections and $61 \%$ of the $N$ gonorrhoeae infections registered concerned men between 20 and 49 years of age; this percentage is respectively $20 \%$ and $49 \%$ for the cases reported afterwards $\left(\mathrm{p}<10^{-7}\right)$. The percentage of women between 20 and 49 years of age went up from $43 \%$ to $63 \%$ for $C$ trachomatis infections and from $27 \%$ to $38 \%$ for $N$ gonorrhoeae infections $\left(p<10^{-7}\right)$.

\section{Sentinel general practitioners}

The same 31 general practitioners participated in the surveillance programme during both registration periods: $1982-3$ and 1988-9. The percentage of weekly report forms returned from the 31 sentinel general practitioners was $87 \%$ in $1982-3$ and $85 \%$ in 1988-9.

Table 2 shows a significant decrease in the frequency of diagnosis of male urethritis by general practitioners in 1988-9 compared to $1982-3$ ( $\mathrm{p}<$ $\left.10^{-3}\right)$.

\section{Discussion}

In order to complement the information from the statutorily notifiable diseases reporting system, new surveillance systems were developed in Belgium. It is indeed widely recognised that only a fraction of

Table 2 Urethritis in males: frequency of diagnosis by 31 general practitioners

\begin{tabular}{llll}
\hline Period & N cases & $\begin{array}{l}\text { N patient } \\
\text { encounters }\end{array}$ & $\begin{array}{l}\text { N cases/100 patient } \\
\text { encounters }\end{array}$ \\
\hline $1982-3$ & 118 & 192085 & 0.06 \\
$1988-9$ & 81 & 211768 & 0.04 \\
\hline
\end{tabular}

communicable disease cases are reported by the notifiable diseases reporting system. ${ }^{13}$ The surveillance system based on sentinel laboratories has indicated that, for instance in 1984 , only $33 \%$ of gonorrhoea cases notified through the sentinel laboratories ( $28 \%$ of the licensed laboratories) were reported. ${ }^{14}$ It seems, for Belgium at least, that this surveillance system of infectious diseases through a network of microbiological laboratories is a good source of epidemiological information.

The fact that the participating laboratories and general practitioners registered during almost $90 \%$ of the registration period is a guarantee of the quality of the registration and a clue to its continuity, and shows that these data can serve as a tool for sentinel surveillance. Thus participation on a voluntary basis seems to be successful and anonymous reporting and regular feedback of results to participants are essential for this success.

An increase in the number of $C$ trachomatis infections, more pronounced among women, was observed up to 1986 . This is possibly related to the extension of the registration to the more widely available methods for antigen detection but also to a growing awareness of and increasing screening for the infection in women. A small decrease in the number of cases of $C$ trachomatis infection in males has been observed since 1987. In Sweden a decrease in the number of laboratory-confirmed chlamydia cases was for the first time observed during 1989, but, in contrast, the decrease occurred mainly among females. ${ }^{1}$

For $N$ gonorrhoeae infections, on the contrary, there was a consistent decrease, more pronounced among men. Thus, between 1983 and 1989, male cases of gonorrhoea fell drastically while cases of chlamydial infection remained largely unchanged. Those laboratories figures compare very well with the general practitioners data showing a decrease in the frequency of diagnosis of male gonococcal and nongonococcal urethritis.

Similar findings have been reported from other European countries. A marked decrease in the prevalence of gonorrhoea has been observed in the Nordic countries, especially in Sweden, during the 1980s.' In Denmark the number of cases of gonorrhoea officially reported has dropped since 1983. The number of laboratory-confirmed cases has also decreased but only since $1985 .^{1}$ A declining trend of gonorrhoea was also found in The Netherlands 
and this since 1981, thus preceding the onset of the AIDS epidemic. ${ }^{2}$ Since 1983 the decline has been further reinforced. In France, a decrease in the number of isolations of gonococci has been registered through a network of laboratories since the beginning of a similar surveillance system in $1986 .{ }^{3}$ The number of gonorrhoea cases diagnosed in a sexually transmitted diseases clinic in Paris fell also between 1986 and 1987. ${ }^{4}$ A recent reduction in male urethritis was also seen through the French Computer Network for Surveillance of Communicable Diseases. ${ }^{5}$ In England and Wales, gonorrhoea has been declining in frequency since 1978. The number of new cases of post-pubertal gonorrhoea reported by NHS genitourinary medicine clinics in 1978 was 57 464, while in 1988 there were 19491 cases, representing a reduction of $66 \%$. The fall was particularly dramatic between 1986 and 1988; reported attendances more than halved between those two years. The male to female ratio has fallen from 1.7: 1 in 1978 to $1 \cdot 4: 1$ in $1988 .^{6}$ Finally, in Switzerland, a decrease has been observed since 1983 in the number of gonorrhoea cases diagnosed in six dermatological clinics. ${ }^{7}$

These consistent trends may partly reflect a change in sexual behaviour resulting from educational campaigns on AIDS in Western and Northern Europe. However the trends in cases of $C$ trachomatis and $N$ gonorrhoeae infections in Belgium seem contradictory. Possible explanations include that the reservoir of $C$ trachomatis infection is more difficult to reach and that case detection is still unsatisfactory, or that these infections are badly treated. Both infections may also affect different groups of population which have been reached differently by educational campaigns. Nearly opposite trends were also documented in Sweden during the first half of the 1980s and were explained by the fact that chlamydial infections are relatively less common in homosexual men and therefore the overall incidence of $C \mathrm{tra}$ chomatis infection is less affected by changes in gay behaviour. ' Therefore, it is possible that the incidence of chlamydial infection will plateau and begin to decline when major reductions in high-risk heterosexual behaviour take place. ${ }^{1}$

We conclude that the declining trend in Western Europe in the incidence of gonococcal infections and of urethritis in men is also occurring in Belgium, but that genital chlamydial infections remain an important public health problem. Continuous registration of some sexually transmitted diseases by laboratories and general practitioners may serve as indicator in the evaluation process of sexual behaviour.

We thank the sentinel laboratories and general practitioners for their collaboration.

Address correspondence to: D Walckiers.

1 Sexually transmitted diseases. Wkly Epidem Rec 1990;41:314-8. 2 van de Laar MJW, Pickering J, van den Hoek JAR, van Griensven GJP, Coutinho RA, Van de Water HPA. Declining gonorrhoea rates in The Netherlands, 1976-88: consequences for the AIDS epidemic. Genitourin Med 1990;66:148-55.

3 Réseau National du Gonocoque : année 1989 + rétrospective 19861988. Laboratoire National de la Santé \& Institut Alfred Fournier. Paris, 1990.

4 Sexually Transmitted Diseases. National network for surveillance of gonococci. Wkly Epidem Rec 1988;32:243-4.

5 Massari V, Valleron AJ. Recent reduction in male urethritis in France (letter). Am J Public Health 1989;79:655.

6 Sexually Transmitted Disease in England and Wales: 19781988. Communicable Disease Report 1991;1(in press).

7 La blennorragie et la syphilis en Suisse. Bulletin des Bundesamtes für Gesundheitswesen 1989;44:592-5.

8 Walckiers D, Vandepitte J, Stroobant A, Cornelis R, Van Casteren V. Une nouvelle méthode de surveillance des maladies infectieuses en Belgique: le réseau "vigie" de laboratoires de microbiologie. Méd Mal Infect 1986;16: 147-50.

9 Stroobant A, Van Casteren V, Thiers G. Surveillance systems from primary-care data: surveillance through a network of sentinel general practitioners. In: Eylenbosch WJ, Noah ND, eds. Surveillance in Health and Disease. Oxford: Oxford University Press, 1988:62-74.

10 Stroobant A, Piot P, Meheus A, Fontaine J. Les uretrites chez l'homme en Belgique. Résultats de l'enregistrement par un réseau de médecins généralistes. Rev Epidémiol Santé Publique 1985;33:432-6.

11 Van Casteren V, Van der Veken J. La Morbidité en Belgique en 1988-1989. Réseau d'Enregistrement des Médecins Vigies. Institut d'Hygiène et d'Epidémiologie, Bruxelles (Belgique), 1990 (rapport D/1990/2505/13).

12 Meheus AZ, Van der Auwera JC, Eylenbosch WJ. De aangifte van venerische ziekten. Onderzoek in de regio Antwerpen in 1974. Belg Arch Soc geneeskd en Hyg 1975;3:168-80.

13 Marier R. The reporting of communicable diseases. Am J Epidemiol 1977;105:587-9C.

14 Walckiers D, Piot P, Stroobant A, Cornelis R, Lion J, Van Casteren V. Aspects épidémiologiques des infections à Neisseria gonorrhoeae en Belgique. Rev Epidémiol Santé Publique 1989;37:7-12.

Accepted for publication 3 June 1991 